\title{
Dissection of the inhibition of cardiac ryanodine receptors by human glutathione transferase GSTM2-2
}

\author{
Dan Liu, Ruwani Hewawasam, Suzy M. Pace, Esther M. Gallant, \\ Marco G. Casarotto, Angela F. Dulhunty ${ }^{1, *}$, Philip G. Board ${ }^{1}$ \\ Division of Molecular Bioscience, John Curtin School of Medical Research, Australian National University, PO Box 334, Canberra, \\ ACT 2601, Australia
}

\section{A R T I C L E I N F O}

Article history:

Received 5 November 2008

Accepted 22 December 2008

Keywords:

Glutathione transferase GSTM2-2

Cardiac RyR2 channels

Skeletal RyR1 channels

Calcium release from cardiac

sarcoplasmic reticulum

Calcium release from skeletal

sarcoplasmic reticulum

Lipid bilayer single channel

experiments

\begin{abstract}
A B S T R A C T
The muscle specific glutathione transferase GSTM2-2 inhibits the activity of cardiac ryanodine receptor (RyR2) calcium release channels with high affinity and activates skeletal RyR (RyR1) channels with lower affinity. To determine which overall region of the GSTM2-2 molecule supports binding to RyR2, we examined the effects of truncating GSTM2-2 on its ability to alter $\mathrm{Ca}^{2+}$ release from sarcoplasmic reticulum (SR) vesicles and RyR channel activity. The C-terminal half of GSTM2-2 which lacks the critical GSH binding site supported the inhibition of RyR2, but did not support activation of RyR1. Smaller fragments of GSTM2-2 indicated that the C-terminal helix 6 was crucial for the action of GSTM2-2 on RyR2. Only fragments containing the helix 6 sequence inhibited $\mathrm{Ca}^{2+}$ release from cardiac SR. Single RyR2 channels were strongly inhibited by constructs containing the helix 6 sequence in combination with adjacent helices (helices 5-8 or 4-6). Fragments containing helices 5-6 or helix 6 sequences alone had less well-defined effects. Chemical cross-linking indicated that C-terminal helices 5-8 bound to RyR2, but not RyR1. Structural analysis with circular dichroism showed that the helical content was greater in the longer helix 6 containing constructs, while the helix 6 sequence alone had minimal helical structure. Therefore the active centre of GSTM2-2 for inhibition of cardiac RyR2 involves the helix 6 sequence and the helical nature of this region is essential for its efficacy. GSTM2-2 helices 5-8 may provide the basis for RyR2-specific compounds for experimental and therapeutic use.
\end{abstract}

(C) 2009 Elsevier Inc. All rights reserved.

\section{Introduction}

The ryanodine receptor (RyR) channel is essential for $\mathrm{Ca}^{2+}$ release from the sarcoplasmic reticulum (SR) of striated muscle. The cardiac RyR (RyR2) is critical in cardiac myocytes for heart beat, while the skeletal RyR (RyR1) is essential for all voluntary movement supported by skeletal muscle. The mechanisms by which endogenous compounds modulate RyR activity are important to understanding the in vivo function of the channels and their contribution to cardiac output and to locomotion in health and diseased states. Such mechanistic insights also provide a basis for therapy in disease.

The glutathione transferase structural (GST) family are a class of endogenous RyR modulators that produce strong inhibition of the cardiac RyR2, but not skeletal RyR1, channels. This action has been observed with CLIC-2 (chloride intracellular channel type 2), GSTO1-1 and the muscle specific GSTM2,

\footnotetext{
* Corresponding author. Tel.: +61 26125 4491; fax: +61 261254761.

E-mail address: angela.dulhunty@anu.edu.au (A.F. Dulhunty).

${ }^{1}$ Board and Dulhunty made equal senior author contributions to the manuscript. 0006-2952/\$ - see front matter (C) 2009 Elsevier Inc. All rights reserved. doi:10.1016/j.bcp.2008.12.024
} 
all of which have strong inhibitory actions on the RyR2 channels and weak excitatory actions on RyR1 [1-4]. The CLIC2 protein belongs to the GST structural family, it is expressed in the heart and it is one of the few endogenous inhibitors of RyR2 [1,2]. The effects are easily reversible when the GSTs are washed out of the solution, indicating the reaction depends on reversible ligand binding rather than the formation of a disulphide bond. The actions of CLIC-2 on RyR2 have been shown to be redox sensitive, with inhibitory actions being particularly strong under conditions likely to be encountered in ischaemia [5]. The selective inhibition of cardiac RyR2 by the muscle specific GSTM2-2 suggests that the active part of the GST molecule may be a useful therapeutic agent for cardiac therapy, but would be less useful if the action of the GST depended on its ezymatic activity. The parts of the GST molecule that interact with the RyR2 channel and their mechanism of action remain unknown. Therefore the aim of this paper was to determine the mechanism whereby the muscle specific GSTM2-2 interacts with the RyR. To this end we examined deletion mutants containing progressively smaller parts of the GSTM2-2 molecule that inhibited RyR2. The efficacy of the constructs in inhibiting RyR2 activity was assessed in experiments measuring $\mathrm{Ca}^{2+}$ release from the cardiac SR and in single channel experiments.

\section{2.}

\section{Methods and materials}

\subsection{Reagents}

The restriction enzymes were purchased from New England Biolabs (Genesearch Pty. Ltd. 14 Technology Drive, Arundel, Queensland 4214, Australia), and T4 DNA ligase was from Promega (Suite W3A, Level 3, Westside Building, South Sydney Corporate Park, 75-85 O'Riordan Street, Alexandria NSW 2015). The Pfu Turbo DNA polymerase from Stratagene was used in polymerisation chain reactions (PCR). Plasmid purification kit and PCR fragment purification kit were from Qiagen. All other chemicals were purchased from Sigma-Aldrich Pty. Ltd.; PO Box 970, Castle Hill, NSW 1765, Australia.

\subsection{Cloning, expression and purification of GSTM2-2C terminus fragments}

General DNA techniques were as described by Ref. [6]. The DNA fragments of the GSTM2-2 gene were obtained by PCR using plasmid pKKGSTM2 [7] as template. The PCR products were cloned into vector pHUE [8]. The point mutation construct (GSTM2-2Y7F) was generated by overlapping PCR. The sequences of all the constructs were confirmed by DNA sequencing. The expression and purification of recombinant proteins using the pHUE system were as described previously $[8,9]$. Proteins or peptides expressed in this system have no additional purification tag residues remaining after purification.

\section{3. $\left[{ }^{35}\right.$ S]GSTM2-2 H5678 expression and purification}

The protein fragment containing GSTM2-2 helices 5-8 (H5678) was metabolically labelled with $\left[{ }^{35} \mathrm{~S}\right]$ methionine as follows. Briefly, Escherichia coli strain BL21/DE3 carrying the plasmid
pHUE M2 H5678 was grown in Luria-Bertani (LB) broth to midlog phase. Bacterial cells were collected by centrifugation and washed twice with M9 minimal medium. Bacterial cells were then grown in $\mathrm{M} 9$ minimal medium at $37^{\circ} \mathrm{C}$ for $1 \mathrm{~h}$ with isopropylthio- $\beta$-D-galactoside added to a final concentration of $1 \mathrm{mM}$. Trans $\mathrm{s}^{35} \mathrm{~S}$-label (MP Biomedicals, Inc., $1 \mathrm{mCi} / 10 \mathrm{ml}$ ) was then added and the cells allowed to grow for $3 \mathrm{~h}$ at $37^{\circ} \mathrm{C}$. The bacterial cells were pelleted and resuspended in buffer $\mathrm{A}$ (300 $\mathrm{mM} \mathrm{NaCl}, 50 \mathrm{mM}$ phosphate buffer $\mathrm{pH}$ 6.5) and then were lysed by using a FRENCH Pressure cell (1000 psi). After centrifugation at $25,000 \times g$ for $20 \mathrm{~min}$, GSTM2-2 H5678 was purified from the clear lysate by affinity chromatography using nickel-agarose and the N-terminal His-ubiquitin tag removed by specific proteolytic cleavage [8]. The purified protein was dialysed in HEPES buffer $(200 \mathrm{mM} \mathrm{KCl}, 50 \mathrm{mM}$ HEPES pH 7.4) at $4{ }^{\circ} \mathrm{C}$.

\subsection{Chemical cross-linking analysis}

The thiol-cleavable, $12 \AA$ cross-linker dithiobis-succinimidylpropionate (DSP, Pierce; P.O. Box 117, Rockford, IL 61105, USA) was used in the experiments. DSP was freshly dissolved in dimethyl sulfoxide and added to a reaction mixture to a final concentration of $1 \mathrm{mM}$. The reaction mixtures contain SR vesicles $(20 \mu \mathrm{g}$ protein from rabbit skeletal muscle or $60 \mu \mathrm{g}$ protein from sheep cardiac muscle) and $\left[{ }^{35} \mathrm{~S}\right]$-labelled GSTM22 H5678 protein $(2 \mu \mathrm{g})$ in HEPES buffer. The reactions were carried out at room temperature for $30 \mathrm{~min}$ and then stopped by adding ammonium acetate to a final concentration of $50 \mathrm{mM}$.

An equal volume of sample buffer ( $8 \mathrm{M}$ urea, $2 \mathrm{M}$ thiourea, $3 \%$ SDS, $50 \mathrm{mM}$ Tris- $\mathrm{HCl} \mathrm{pH} \mathrm{6.8)} \mathrm{was} \mathrm{added} \mathrm{to} \mathrm{the} \mathrm{reaction}$ mixture and heated at $37^{\circ} \mathrm{C}$ for $10 \mathrm{~min}$. The protein profiles were analysed by SDS-polyacrylamide gel electrophoresis, performed according to Laemmli [10] using a Bio-Rad Miniprotean II gel system and a gradient polyacrylamide (2.6-6\%) gel. Western blotting was carried out as described previously [4]. Anti-ryanodine receptor antibody was obtained from Affinity Bioreagents (28 Monro Ave, Kirrawee Sydney 2232 PO Box 78, Gymea 227, Australia), and it was diluted (1:5000) in the working solution. In order to detect $\left[{ }^{35} \mathrm{~S}\right]$-labelled H5678 protein, the gel was fixed in water:methanol:acetic acid $=7: 2: 1$ and dried at $80^{\circ} \mathrm{C}$ under vacuum. The dried gel was exposed to an X-ray film.

\subsection{Preparation of SR}

These techniques are described in Refs. [1,2,4,11]. Briefly, cardiac SR was prepared from sheep heart. Skeletal SR was isolated from the back and leg muscles of New Zealand White rabbits, and heavy SR was collected from the 35-45\% (w/v) interface of a discontinuous sucrose gradient, centrifuged and resuspended. Cardiac and skeletal SR vesicles were divided into small aliquots frozen and stored either in liquid $\mathrm{N}_{2}$ or at $-70{ }^{\circ} \mathrm{C}$ until use.

\section{6. $\mathrm{Ca}^{2+}$ release from $\mathrm{SR}$}

The methods for measuring $\mathrm{Ca}^{2+}$ release have been described previously $[5,12]$ and are illustrated in Fig. 1. A Cary 3 
spectrophotometer was used to monitor extravesicular $\mathrm{Ca}^{2+}$ at $710 \mathrm{~nm}$, using the $\mathrm{Ca}^{2+}$ indicator antipyrylazo III (Fig. 1A). Cardiac SR vesicles $(100 \mu \mathrm{g} / \mathrm{ml})$ were added to a solution containing $100 \mathrm{mM} \mathrm{KH}_{2} \mathrm{PO}_{4}, 0.4 \mathrm{mM}$ antipyrylazo III, $1 \mathrm{mM}$ $\mathrm{Na}_{2} \mathrm{ATP}$ and $4 \mathrm{mM} \mathrm{MgCl}{ }_{2}$ controlled at a temperature of $25^{\circ} \mathrm{C}$ and magnetically stirred. Extravesicular $\mathrm{Ca}^{2+}$ was measured with the $\mathrm{Ca}^{2+}$ indicator antipyrylazo III at $710 \mathrm{~nm}$. Cardiac SR was then added to the cuvette, causing an increase in $\left[\mathrm{Ca}^{2+}\right]$ which then declined as $\mathrm{Ca}^{2+}$ was taken up by the $\mathrm{Ca}^{2+}$ ATPase which was activated by MgATP. The SR was then loaded with four additions of $7.5 \mu \mathrm{M} \mathrm{Ca}{ }^{2+}(30 \mu \mathrm{M}$ total). Thapsigargin $(2.25 \mu \mathrm{M})$ was added to block the $\mathrm{Ca}^{2+}$-ATPase, and then
$5 \mathrm{mM}$ caffeine for cardiac SR or $0.5 \mathrm{mM}$ caffeine for skeletal $\mathrm{SR}$. Ruthenium red was added to confirm that $\mathrm{Ca}^{2+}$ release was through the RyR and finally $\mathrm{Ca}^{2+}$ ionophore (A23187) to release $\mathrm{Ca}^{2+}$ remaining in the $\mathrm{SR}$. The $\mathrm{SR}$ vesicles were incubated for $20 \mathrm{~min}$ prior to the start of the experiment with the GSTM2-2 construct in vehicle buffer or with vehicle buffer alone. The same concentrations of GSTM2-2 construct in vehicle buffer or with vehicle buffer alone were added to the cuvette solution prior to vesicle addition. A calibration curve of optical density changes with four additions of $12.5 \mu \mathrm{M} \mathrm{CaCl}_{2}$. The calibration curve was not altered by the presence of GSTM2-2, caffeine or ruthenium red. The initial

(A)
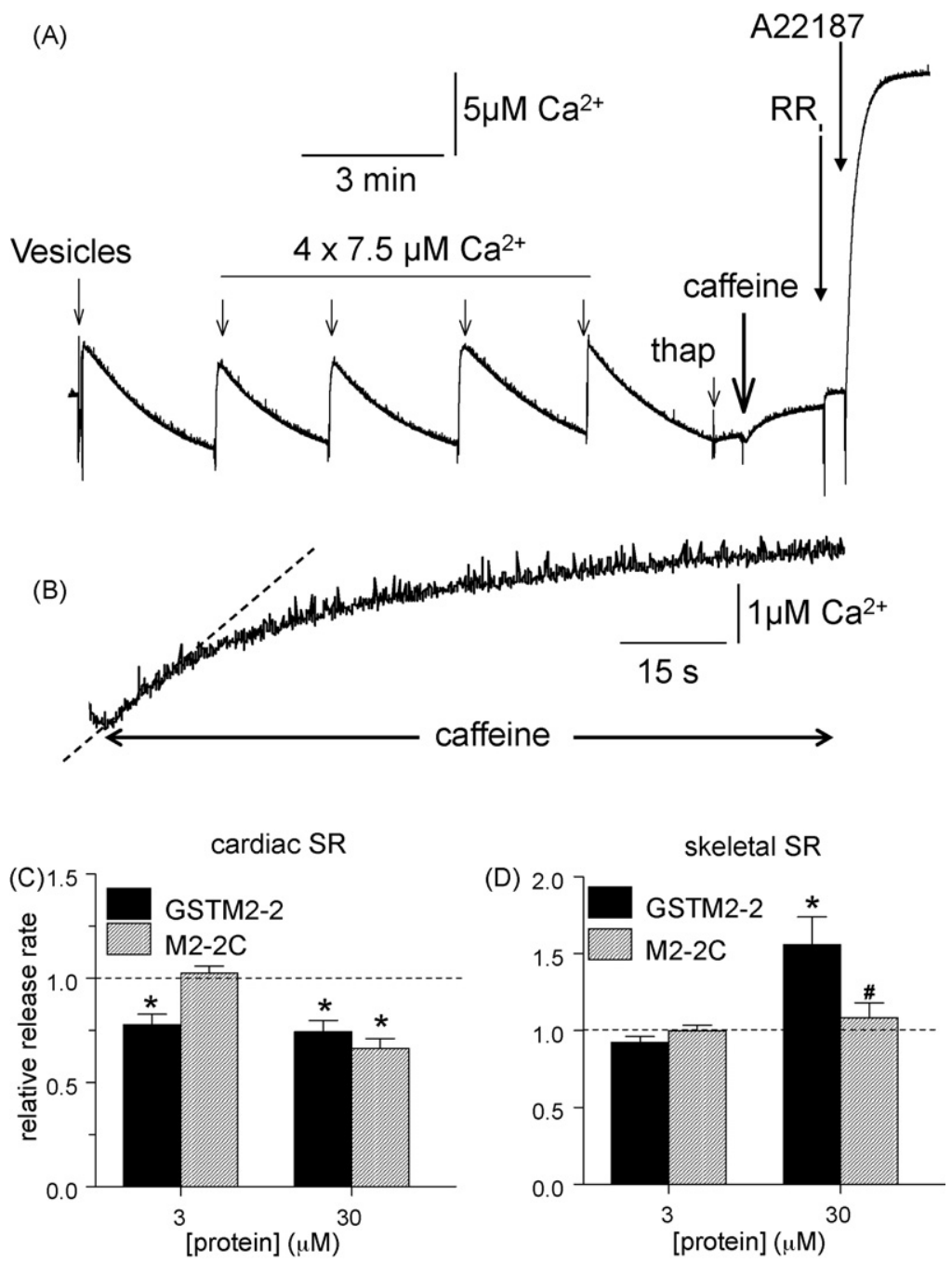

Fig. 1 - Measurement of $\mathrm{Ca}^{2+}$ release from SR vesicles and the effects of the C-terminal half of GSTM2-2. The record in (A) shows a typical experiment measuring $\mathrm{Ca}^{2+}$ release from cardiac SR vesicles. $\left[\mathrm{Ca}^{2+}\right.$ ] was monitored with antipyralazo III absorbance. SR vesicles were added to the cuvette, loaded with $\mathrm{Ca}^{2+}$ added in four aliquots of $7.5 \mu \mathrm{M}$. The added $\mathrm{Ca}^{2+}$ was transported into the vesicles by the $\mathrm{SR} \mathrm{Ca}^{2+} \mathrm{ATPase}$ which was subsequently blocked by thapsigargin (thap). $\mathrm{Ca}^{2+}$ release was then initiated with $5 \mathrm{mM}$ caffeine (or $0.5 \mathrm{mM}$ caffeine with skeletal SR). Ruthenium red (RR) was added to confirm that release was through RyR2. Remaining $\mathrm{Ca}^{2+}$ was released by the ionophore A23187, showing that a non-caffeine releasable pool of $\mathrm{Ca}^{2+}$ remained in the $\mathrm{SR}$ and that antipyralazo was not saturated with $\mathrm{Ca}^{2+}$ during the caffeine-induced response. (B) The caffeine transient was expanded and the initial rate of release (broken line) measured. Vesicles were equilibrated with GSTM2-2 protein constructs (or buffer in control experiments) for $20 \mathrm{~min}$ on ice before the experiment commenced. (C and D) Average data (hatched bins) for relative rates of caffeine-induced $\mathrm{Ca}^{2+}$ release from cardiac (C) and skeletal (D) SR, indicating that the C-terminal construct (M2-2C) inhibits $\mathrm{Ca}^{2+}$ release from cardiac SR at $30 \mu \mathrm{M}$ but does not activate $\mathrm{Ca}^{2+}$ release from skeletal $S R$. $\mathbf{N}=5$ for each data set. 
rate of caffeine-induced $\mathrm{Ca}^{2+}$ release was measured (Fig. 1B). An ATP regenerating system was not used. Since the protocol followed in these experiments was tightly controlled, the ATP concentration would have been the same during drug exposure in each experiment, and ATP would have been utilized at the same rate and varying with time in the same way from experiment to experiment. Since the rate of $\mathrm{Ca}^{2+}$ uptake during loading was the same in the first and fourth loading step (Fig. 1A) we assume that ATP was not severely depleted.

\subsection{Single channel activity}

Artificial lipid bilayers separating cis and trans solutions were formed $[1,2,4,11]$. Single channel parameters were obtained using the Channel 2 program (developed by P.W. Gage and M. Smith, John Curtin School of Medical Research, Canberra, Australia). In general channels incorporated with their cytoplasmic surface of the SR facing the cis solution and this was confirmed by characteristic increase in channel activity with changes in cis $\mathrm{Ca}^{2+}$ concentration chamber. For channel incorporation, the solutions were: cis: $230 \mathrm{mM}$ Cs methanesulphonate $\left(\mathrm{CsCH}_{3} \mathrm{O}_{3} \mathrm{~S}\right), 20 \mathrm{mM} \mathrm{CsCl}, 1 \mathrm{mM} \mathrm{CaCl}_{2}$, and $10 \mathrm{mM} \mathrm{N}$-tris[hyroxymethyl]methyl-2-aminoethanesulfonic acid (TES, pH 7.4); and trans: $30 \mathrm{mM} \mathrm{CsCH}_{3} \mathrm{O}_{3} \mathrm{~S}, 20 \mathrm{mM}$ $\mathrm{CsCl}, 1 \mathrm{mM} \mathrm{CaCl}$, and $10 \mathrm{mM}$ TES (pH 7.4). After channel incorporation, trans $\left[\mathrm{Cs}^{+}\right]$was raised to $250 \mathrm{mM}$ with addition of $200 \mathrm{mM} \mathrm{CsCH} \mathrm{O}_{3} \mathrm{~S}$. Experiments were carried out at $23 \pm 2{ }^{\circ} \mathrm{C}$. Bilayer potential is expressed as the cytoplasmic solution relative to luminal solution and was changed every $30 \mathrm{~s}$ between $+40 \mathrm{mV}$ and $-40 \mathrm{mV}$. Current was recorded continuously throughout the experiment at $5 \mathrm{kHz}$ and was filtered at $1 \mathrm{kHz}$. The open probability $\left(P_{\circ}\right)$ was measured using either a threshold discriminator (when one channel only opened) or from mean current, I' (when bilayers contained more than one active channel). For threshold detection, a threshold was set outside the noise at $\sim 20 \%$ of the maximum open conductance. Currents exceeding the threshold were detected as channel openings. The mean current $\left(I^{\prime}\right)$ is the average of all data points in a record. Relative $I^{\prime}$ is approximately equal to relative $P_{\mathrm{o}}$. The record in Fig. 1 shows that the cardiac SR contains a substantial $\mathrm{Ca}^{2+}$ pool that does not respond to caffeine and is due to the presence of longitudinal SR which lacks RyR channels, but contains $\mathrm{K}^{+}$and $\mathrm{Cl}^{-}$channels. Such channels were not seen in lipid bilayer experiments which were performed in the presence of $\mathrm{CsCH}_{3} \mathrm{O}_{3} \mathrm{~S}\left(\mathrm{~K}^{+}\right.$channels are impermeable to $\mathrm{Cs}^{+}$, and $\mathrm{Cl}^{-}$channels are impermeable to $\mathrm{CH}_{3} \mathrm{O}_{3} \mathrm{~S}^{-}$). All channels used in the analysis were blocked by ruthenium red at the end of the experiment to confirm that they were RyR channels.

\subsection{Circular dichroism}

Constructs were diluted to $1 \mathrm{mg} / \mathrm{ml}$ in $10 \mathrm{mM}$ phosphate buffer and $\mathrm{pH}$ adjusted to 8.0. CD spectra were collected at $22{ }^{\circ} \mathrm{C}$ on a Chirascan CD spectrometer (Applied Photophysics Ltd., 203/205 Kingston Road, Leatherhead, Surrey KT22 7PB, United Kingdom). Ten spectra were collected, averaged and subjected to a smoothing function.

\subsection{Statistics}

Average data is presented as mean \pm S.E.M. The significance of differences between control and test values were tested using a Student's t-test for paired data or a sign test [13], as appropriate. A $P$ value of $<0.05$ was considered significant. The sign test is a non-parametric distribution-free test (http:// www.graphpad.com/quickcalcs/binomial2.cfm) which is applicable to most single channel data.

\section{Results}

RyR channel activity was assessed in two ways in this study. Firstly, by measuring $\mathrm{Ca}^{2+}$ release from SR vesicles and secondly by examining the activity of single channels incorporated into artificial lipid bilayers. The rate of $\mathrm{Ca}^{2+}$ release provides a population response in a preparation that is closer to the intact cell in that the RyR channel retains its normal structural and functional association with other proteins in the SR membrane and the lumen of the SR. Fig. $1 \mathrm{~A}$ and $\mathrm{B}$ shows a typical spectrophotometric experiment in which cardiac SR vesicles were loaded with $\mathrm{Ca}^{2+}$, the SERCA $\mathrm{Ca}^{2+}$ pump (sarcoplasmic, endoplasmic reticulum $\mathrm{Ca}^{2+}$ ATPase) blocked with thapsigargin, and $\mathrm{Ca}^{2+}$ release through RyR2 stimulated with caffeine. The single channel analysis examines individual RyR molecules and provides information on the kinetics of channel activity. To explore the region of GSTM2-2 that interacts with RyR channels, we designed two deletion mutants equivalent to the $\mathrm{N}$ - and $\mathrm{C}$-terminal halves of the protein. The N-terminal fragment (GSTM2-2N) containing the characteristic mixture of three $\alpha$ helices and four $\beta$ strands found in thioredoxin fold of GST proteins [14,15] was insoluble and could not be examined. The C-terminal half of GSTM2-2 (GSTM2-2C) containing five $\alpha$-helices (helices 4-8) was soluble and its effect on RyR channels was examined in $\mathrm{Ca}^{2+}$ release and single channel experiments.

\subsection{Action of the C-terminal half of GSTM2-2}

GSTM2-2C inhibited $\mathrm{Ca}^{2+}$ release from cardiac SR with similar efficacy to the wild-type GSTM2-2 at $30 \mu \mathrm{M}$, although it was less effective than GSTM2-2 at $3 \mu \mathrm{M}$ (Fig. 1C). There was a significant $\sim 33 \%$ reduction in the rate of release with $30 \mu \mathrm{M}$ GSTM2-2C. Also contrary to expectations, the C-terminal construct was inactive when applied to skeletal SR preparations. The rate of caffeine-induced $\mathrm{Ca}^{2+}$ release was not significantly altered by $30 \mu \mathrm{M}$ GSTM2-2C, in contrast to the activation seen with the wild-type GSTM2-2 at the same concentration (Fig. 1D).

The effects GSTM2-2C on single channel activity were consistent with the effects on $\mathrm{Ca}^{2+}$ release. Indeed, GSTM2-2C produced significantly greater inhibition of single cardiac RyR2 channel activity than the full length protein (Fig. 2). The average relative open probability in Fig. 2 and in subsequent figures includes data from records at $+40 \mathrm{mV}$ and $-40 \mathrm{mV}$ since the response to GSTM2-2 constructs was the same at both potentials, with one exception (in Fig. 8 below) where data from the two potentials is shown separately. When $30 \mu \mathrm{M}$ GSTM2-2C was added to the cytoplasmic solution the average 


\section{cardiac channels}

(A)

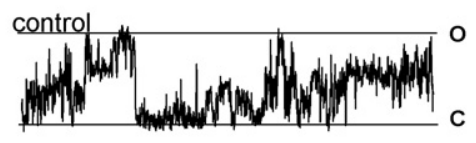

$15 \mu \mathrm{M} \mathrm{M} 2-2 \mathrm{C}$

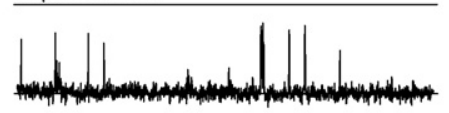

washout

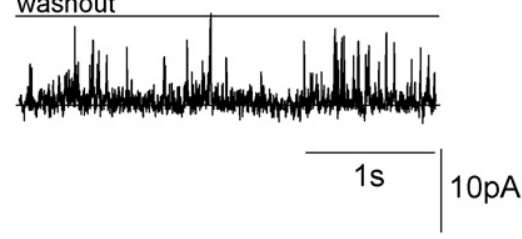

(B)

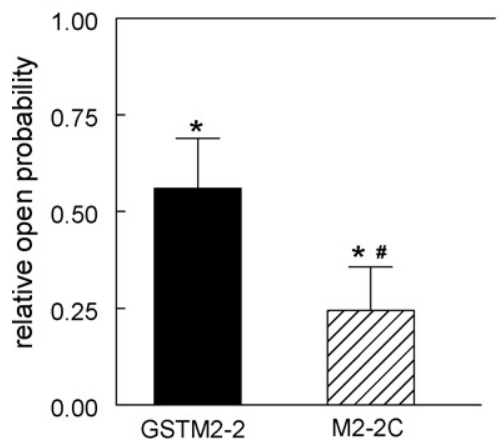
$10 \mathrm{pA}$ skeletal channels

(C)
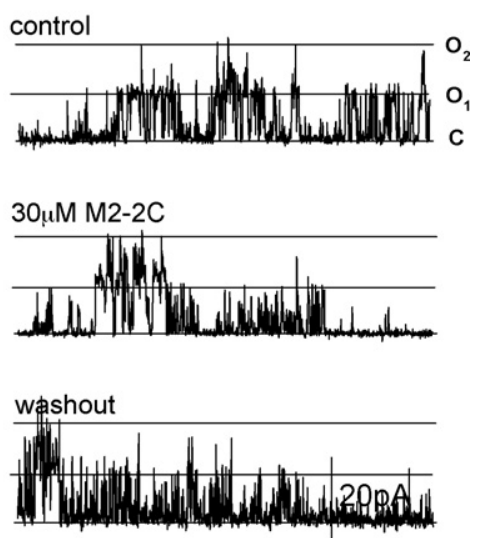

Fig. 2 - The C-terminal half of GSTM2-2 supports inhibition of cardiac RyR2 channels but not activation of RyR1 channels. Recordings from cardiac RyR2 (A) and skeletal RyR1 (C) channels at $+\mathbf{4 0} \mathbf{~ m V}$, during the period before addition of GSTM2-2C to the cis chamber (control), in the presence of the protein (M2-2C) and after perfusion of the cis chamber to remove the protein (washout), showing inhibition of RyR2 by $15 \mu \mathrm{M}$ GSTM2-2C (A) but no effect of $30 \mu \mathrm{M}$ GSTM2-2C on RyR1 (C). Channel opening is upward from the closed level (c) to the maximum single channel current (o). When two channels are present in the bilayer, one opens alone to a maximum current of $o_{1}$ or two channels open simultaneously to $o_{2}$. (B and D) show average data for GSTM2-2C (stippled bins) and GSTM2-2 (filled bins), showing enhanced inhibition of RyR2, but no effect on RyR1. Data from five experiments was analysed for each data set. Asterisks (*) indicate a significant difference from control values. Hatch (\#) indicates that the effect of M2-2C is significantly different from the effect of the full length GSTM2-2 protein.

relative open probability fell to $\sim 25 \%$ of control (Fig. 2B). This was significantly greater than the fall to $\sim 56 \%$ with the full length protein. The decrease in activity was reversed when the protein was perfused from the cis chamber with activity increasing by 2-3-fold in two of the channels in which washout was achieved (Fig. 2A). GSTM2-2C did not affect skeletal RyR1 channels (Fig. 2C), consistent with its failure to enhance $\mathrm{Ca}^{2+}$ release from skeletal SR, in contrast to the significant activation produced by the wild-type GSTM2-2 (Fig. 2D).

These results show clearly that the inhibitory action of GSTM2-2 on the cardiac RyR2 is fully supported by the Cterminal half of the protein, while the activation of RyR1 is not supported and presumably involves an interaction with an $\mathrm{N}$ - terminal part of GSTM2-2. Thus the C-terminal half of GSTM22 is highly specific for RyR2. Importantly, the results show that the inhibitory action of GSTM2-2 on cardiac RyR channels does not depend on the N-terminus which contains the critical catalytic site. The implications are that the C-terminal part of the protein could be used pharmacologically to target RyR2 channels without any complications arising from its possible enzyme action or its action on skeletal muscle.

\subsection{Which C-terminal regions contribute to inhibition of RyR2 channels?}

Constructs containing various combinations of the five Cterminal helices (Fig. 3) were designed to further identify the 
(A) Thioredoxin Domain ${ }_{90-112}^{\text {H4 }}{ }_{119-141}^{\text {H5 }}$
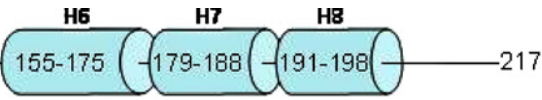

(B)

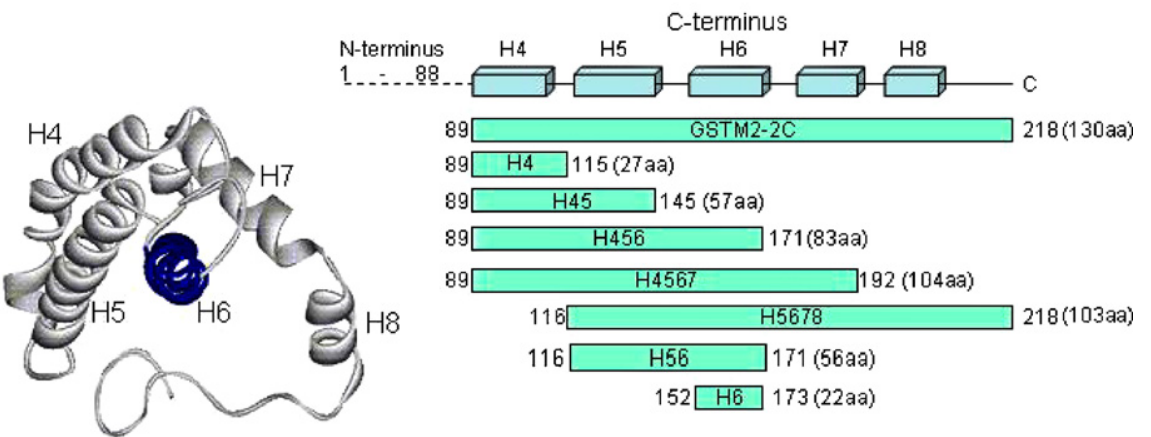

Fig. 3 - The GSTM-2-2 C-terminus. (A) The position of helices 4-8 in C-terminal domain of the human GSTM2-2. (B) The human GSTM2-2 structure showing the alpha helices in the C-terminal domain. (C) Illustration of the seven different constructs of the C-terminal regions used in the following experiments.

parts of GSTM2-2C involved in the interaction with RyR2. Most constructs were expressed (Section 2), but shorter fragments containing residues forming only one helix (helix 4 or helix 6) were synthesised. The average data for effects on $\mathrm{Ca}^{2+}$ release from SR vesicles shows that the four recombinant fragments containing helix 6 (H4567, H5678, $\mathrm{H} 456$ and H56) inhibited $\mathrm{Ca}^{2+}$ release from cardiac SR, but were inactive when applied to skeletal SR (Fig. 4). H56 produced significant inhibition to $80 \%$ of control at a concentration of only $3 \mu \mathrm{M}$. Higher concentrations of H56 were not examined because a time-dependent interaction with antipyralazo III reduced the $\mathrm{Ca}^{2+}$ sensitivity of the dye. Single channel data (below) indicates that H56 has unusual, possibly non-specific effects that were not further investigated. The helix 6 peptide (H6) produced a small but significant reduction in $\mathrm{Ca}^{2+}$ release from cardiac SR at $15 \mu \mathrm{M}$ and $30 \mu \mathrm{M}$. None of the helix 6 constructs altered $\mathrm{Ca}^{2+}$ release from skeletal SR, while constructs lacking helix 6 ( $\mathrm{H} 4$ and $\mathrm{H} 45)$ failed to influence $\mathrm{Ca}^{2+}$ release from either cardiac or skeletal SR. In addition, a construct containing the sequences encompassing helices 7 and 8 (H78) was examined in one experiment and the release rate was no less than the control release rates (data not shown).

Selected constructs, H5678, H456, H56 and H6, were examined in single channel experiments to determine whether the effects on $\mathrm{Ca}^{2+}$ release could be attributed to a change in channel gating or to a pore block. In addition, the single channel experiments provide a measure of the effects of the compounds in the absence of channel activators (ATP and caffeine) which were present in the $\mathrm{Ca}^{2+}$ release assay. It should be noted that the $\mathrm{Ca}^{2+}$ release experiment cannot be performed in the absence of ATP, since this is required for SR loading. The results of the single channel experiments were broadly similar to the SR $\mathrm{Ca}^{2+}$ release data. H5678 and H456 applied to the cytoplasmic solution at concentrations between $1 \mu \mathrm{M}$ and $30 \mu \mathrm{M}$ produced a significant fall in single channel opening (e.g. Fig. 5A) and in average relative open probability (Fig. 5C and E). Curiously, less inhibition was observed with $15 \mu \mathrm{M}$ than $1 \mu \mathrm{M}$ or $5 \mu \mathrm{M}$ in both constructs. The fact that higher concentrations of $\mathrm{H} 456$ were required to see inhibition of $\mathrm{Ca}^{2+}$ release than inhibition of single channels is consistent with the fact that higher concentrations of many compounds are required to see effects in $\mathrm{Ca}^{2+}$ release experiments that are equivalent to effects seen in single channel experiments $[16,17]$. The difference between the two techniques may in part reflect the lower resolution of the $\mathrm{Ca}^{2+}$ release experiments. The reduced inhibition at higher concentrations was not seen in the $\mathrm{Ca}^{2+}$ release experiments. This may have been because of the higher concentrations required to see effects in $\mathrm{Ca}^{2+}$ release experiments. However it may also be that the high concentration effects were specific to the bilayer situation where the channel is in a less physiological environment that in the vesicle study. The important message from these experiments is that the constructs inhibit $\mathrm{Ca}^{2+}$ release from the cardiac SR by reversibly reducing channel open probability rather than by blocking the channels and reducing their conductance. The effects on channel activity were not voltagedependent as, with the exception of H56 (below), similar changes were seen at $+40 \mathrm{mV}$ and $-40 \mathrm{mV}$ and the average data includes values from both potentials. Neither H5678 nor H456 produced any significant change in skeletal RyR1 channel activity (Fig. 5B, D and F). The peptide H6 did not significantly alter the activity of either RyR1 or RyR2 channels (Fig. $5 \mathrm{H}$ and I). Thus the very small inhibition of $\mathrm{Ca}^{2+}$ release by H6, was not mirrored in the single channel situation, reinforcing the minimal activity of this construct. Additional experiments with $\mathrm{H} 6$ and RyR2 in the presence of cytoplasmic ATP (to mimic aspects of the $\mathrm{Ca}^{2+}$ release experiment), also failed to show any significant effect of the peptide (data not shown). Since the effects of $\mathrm{H} 6$ on $\mathrm{Ca}^{2+}$ release were relatively small, the action of this peptide on single channels was not pursued further.

The construct containing the combined helix 5 and 6 sequences (H56) had a complex action on RyR2 channels, with a small but significant inhibition developing at $+40 \mathrm{mV}$ after 812 min exposure to very low concentrations between $1 \mathrm{nM}$ and $10 \mathrm{nM}$ (Fig. 5G). Inhibition was significant at $+40 \mathrm{mV}$ after brief (1-4 min) exposures to higher concentrations between $5 \mu \mathrm{M}$ and $15 \mu \mathrm{M}$, while significant activation was apparent at 
(A)

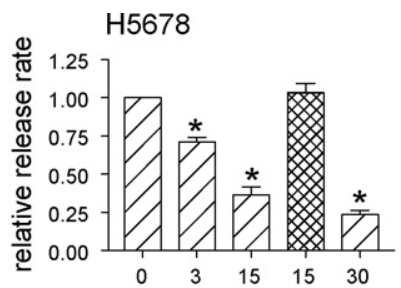

(C)

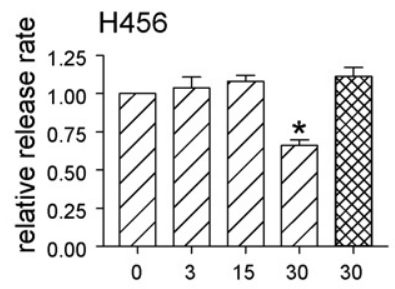

(E)

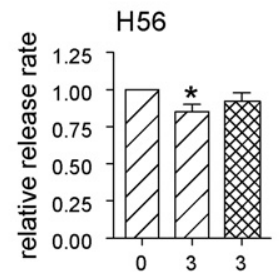

(G)

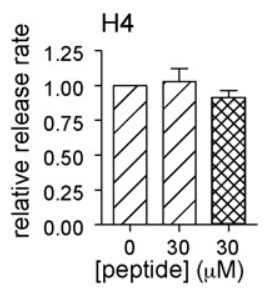

(B)

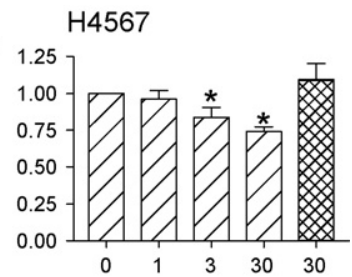

(D)

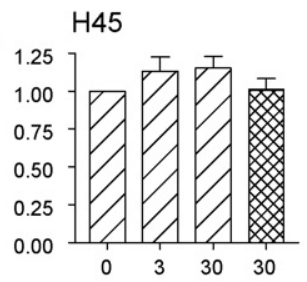

(F)

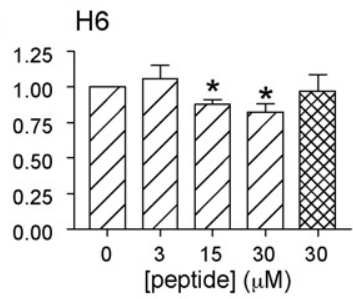

cardiac SR vesicles

skeletal SR vesicles

Fig. 4 - GSTM2-2 constructs containing the helix 6 sequence inhibit $\mathrm{Ca}^{2+}$ release from cardiac SR vesicles, but do not effect $\mathrm{Ca}^{2+}$ release from skeletal SR. (A-G) show average relative rates of $\mathrm{Ca}^{2+}$ induced $\mathrm{Ca}^{2+}$ release from skeletal (double hatched bins) and cardiac (single hatched bins) SR vesicles that had been incubated with H5678 (A), H4567 (B), H456 (C), H45 (D), H56 (E), H6 (F) and H4 (G) at the concentrations indicated on the $\mathrm{Y}$ axis in each graph. $\mathrm{N} \geq \mathbf{5}$ for each data set. Asterisks (*) indicate a significant difference from control values.

$-40 \mathrm{mV}$ after longer 8-12 min exposures to these higher peptide concentrations. The voltage-dependent action of H56 was in contrast to the voltage-independent actions of each of the other constructs and was not explored further as it was likely to be a non-specific action of this particular construct.

Some of the minor differences between the $\mathrm{Ca}^{2+}$ release results and effects of the constructs on single channel activity are likely to be due to the very different conditions during the two types of experiment. The channels are activated by ATP and caffeine during $\mathrm{Ca}^{2+}$ release measurements and may have been phosphorylated by endogenous kinases [18]. The possibility that the recombinant GST constructs contained endogenous kinases is unlikely, but cannot be excluded.

The conclusion from these $\mathrm{Ca}^{2+}$ release and single channel experiments is that $\mathrm{C}$-terminal constructs containing the helix 6 sequence plus sequences corresponding to two or more neighbouring helices produced strong inhibition of cardiac RyR2 by reducing the number of channel openings rather than reducing the single channel conductance, while having no effect on either parameter in the skeletal RyR1. The shorter H6 and $\mathrm{H} 56$ constructs either had no effect or had unusual effects on channel activity. The results indicated that the helix 6 sequence was essential for inhibition of RyR2 channels, but that its structure was also important and required stabilization by surrounding residues or helices. To test this possibility, we examined the structural content of several of the constructs using circular dichroism (CD).

\subsection{Helical content of short C-terminal constructs}

The profile of the CD spectra shown in Fig. 6 indicates that there is a high degree of helical content in GSTM2-2C, H5678, $\mathrm{H} 456$ and H56, while H6 is effectively unstructured. For $\alpha$ helical containing proteins/peptides, the degree of helicity can be assessed by analysis of the CD profile. Predominantly $\alpha$ helical proteins such as poly-lysine display pronounced minima at $208 \mathrm{~nm}$ and $222 \mathrm{~nm}$, while random coil structures display a minima at $195 \mathrm{~nm}$ (http://www.ap-lab.com/circular_dichroism.htm). Compared to GSTM2-2C, there is a small left shift in the $208 \mathrm{~nm}$ minima for the $\mathrm{H} 456$ and H56 constructs. Also, there is a pronounced difference in the $222 \mathrm{~nm}$ minima indicating a reduction in helical content in 
(A)
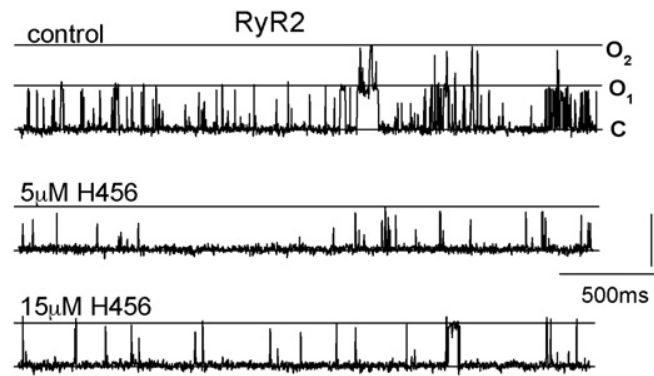

(C)

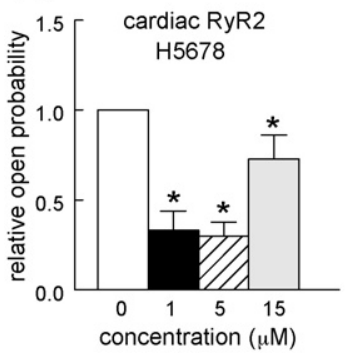

(D)

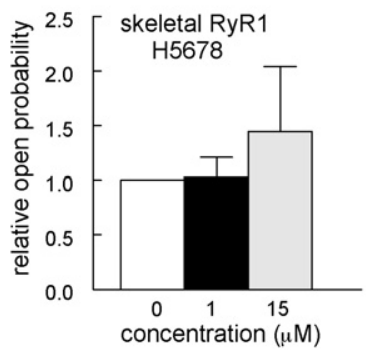

(B)
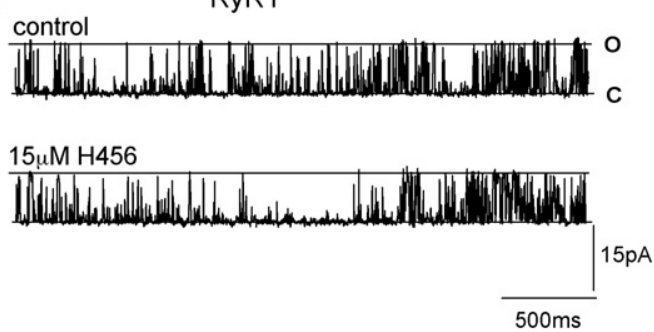

(E)

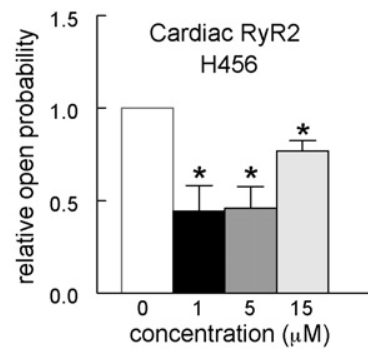

(F)

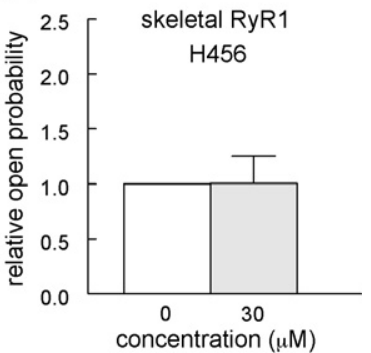

(G)

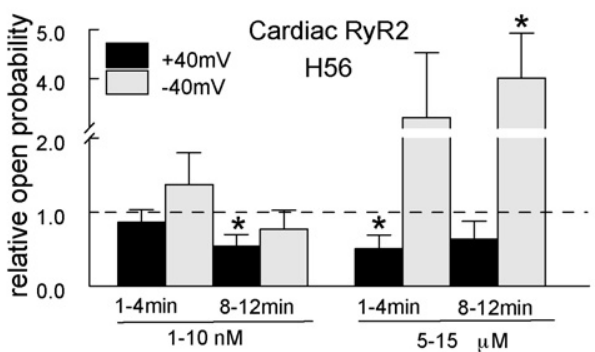

(H)

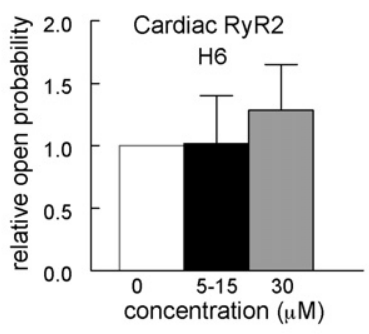

(I)

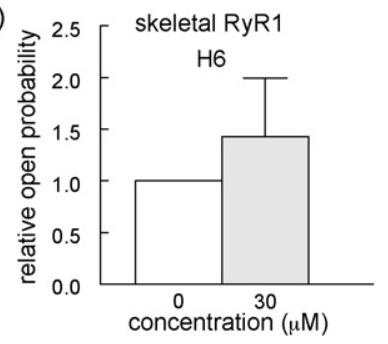

Fig. 5 - Cardiac RyR2 channels are inhibited when longer constructs containing the H6 sequence are added to the cytoplasmic solution, but skeletal RyR1 channels are not affected. (A and B) show 3 s records from cardiac RyR2 and skeletal RyR1 channels respectively at $+40 \mathrm{mV}$, during the period before exposure to $\mathrm{H} 456$ (control), during exposure to $5 \mu \mathrm{M}$ or $15 \mu \mathrm{M} 4456$ as indicated. Channel opening is upward from the closed level (c) to the maximum single channel current (o). When two channels are present in the bilayer, one opens alone to a maximum current of $o_{1}$ or two channels open simultaneously to $\mathrm{o}_{2}$. (C-I) show graphs of average relative open probability in the presence of the indicated concentrations of each construct for cardiac RyR2 (C, E, G and H) or for skeletal RyR1 (D, F and I). Because of its complex action, data for H56 in (E) is shown separately for $+40 \mathrm{mV}$ and $-40 \mathrm{mV}$ and is shown between $1 \mathrm{~min}$ and $4 \mathrm{~min}$ and between $8 \mathrm{~min}$ and $12 \mathrm{~min}$ after adding H56. Cardiac RyR2 channels were inhibited by H5678, H456 and H56. Skeletal RyR1 channels were not significantly affected by any of the constructs. Asterisks (*) indicate a significant difference from control values.

these constructs. In contrast the H5678 construct shows a slight increase in its overall helical content. For the H6 construct no minima were observed near $208 \mathrm{~nm}$ or at $222 \mathrm{~nm}$ and a minimum at $195 \mathrm{~nm}$ suggests that this peptide adopts predominantly a random coil structure. This structural data indicates that all constructs with more than one helical sequence are largely helical in structure and that small inhibitory effect of $\mathrm{H} 6$ on SR $\mathrm{Ca}^{2+}$ release and the lack of effect of $\mathrm{H} 6$ on channels could possibly be related to its lack of helical structure.

\subsection{The H5678 construct binds to RyR2}

In order to demonstrate the physical interaction between GSTM2-2 and RyR protein, the H5678 fragment that produced the strongest inhibition was labelled with ${ }^{35} \mathrm{~S}$ and incubated with cardiac or skeletal muscle SR vesicles. Although a higher affinity effect was seen with H56, it was not used in this experiment because of its more complex and possibly non-specific action (see Section 3.2 above). The cross-linking agent DSP was added following the incubation step to stabilize any complexes between H5678 and associated SR proteins (Section 2). Western blotting showed the position of untreated (Fig. 7A) and cross-linked RyR1 and RyR2 (Fig. 7B) after gradient SDS-PAGE electrophoresis. The blot showing the position of the cross-linked RyR is presented here to show whether any of the ${ }^{35} \mathrm{~S}$ labelled H5678 (shown in the radiograph in $\mathrm{C}$ ) is co-localized with the tetramer. Monomers have a molecular mass of $560 \mathrm{kDa}$ (Fig. 7A) and the crosslinked tetramers are $>2200 \mathrm{kDa}$ (Fig. 7B). RyR monomers have a molecular mass. It is well known that the ability of RyRs to aggregate into tetramers is not dependent on either 
(A)

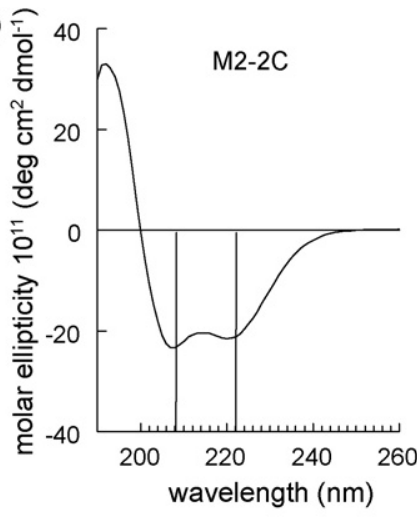

(B)

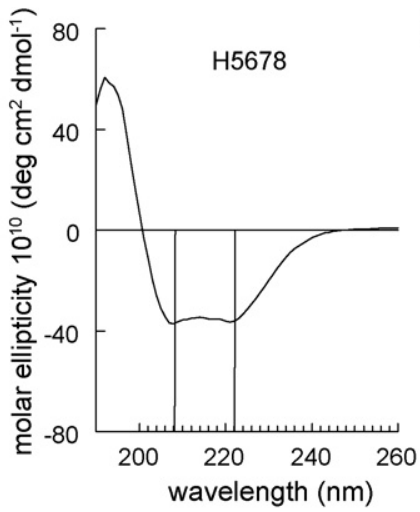

(C)

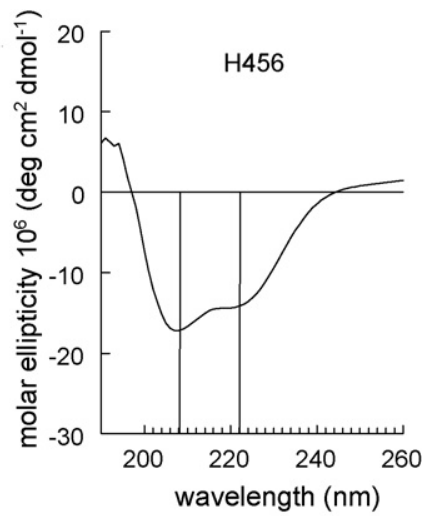

(D)

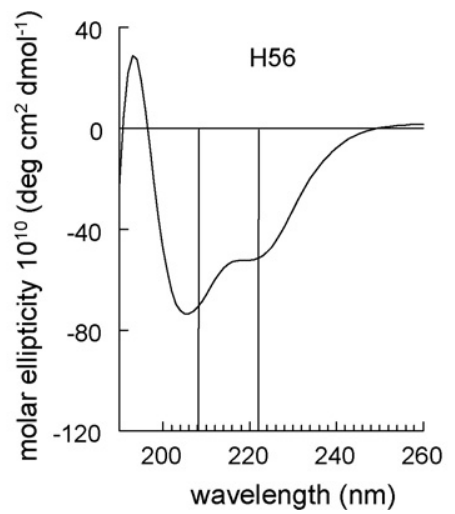

(F)

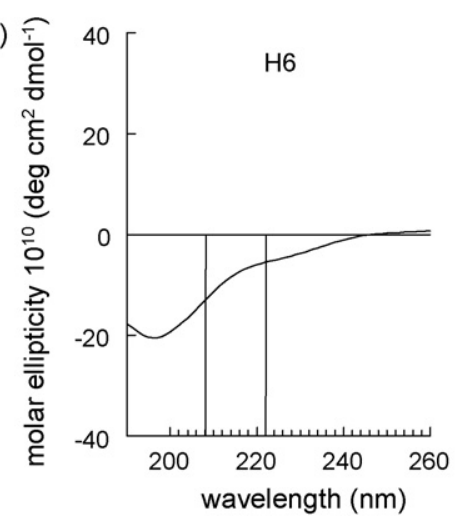

Fig. 6 - Circular dichroism indicates that constructs GSTM2-2C, H5678, H456 and H6 show a high degree of helical content, while $\mathrm{H} 6$ is unstructured. (A-E) show CD spectra for each of the constructs as indicated. Molar ellipticity $\left(\mathrm{deg} \mathrm{cm}^{2} \mathrm{dmol}{ }^{-1}\right)$ is plotted against wavelength in $\mathrm{nm}$. The vertical dotted lines correspond to wavelengths of $208 \mathrm{~nm}$ and $222 \mathrm{~nm}$ where minima are formed by an ideal helix. Helical content is greatest for GSTM2-2C (A), H5678 (B) and H456 (C).

the presence of cross-linking reagents or of GST constructs $[19,20]$. Autoradiography shows that the ${ }^{35}$ S labelled GSTM22 H5678 fragment is co-localized with RyR2 but not RyR1 (Fig. 7C, lanes 3 and 4). No high molecular weight ${ }^{35}$ S labelled species were evident when the experiment was performed in the absence of SR vesicles (Fig. 7C, lane 5). The experiment was repeated three times with similar results. The data from this experiment shows that the sequence containing helices 5, 6, 7 and 8 from the C-terminal domain of GSTM2 can bind to a high molecular weight species from cardiac SR that is similar in size to cross-linked RyR2 tetramer. No crosslinking to skeletal muscle RyR1was detected even though it is

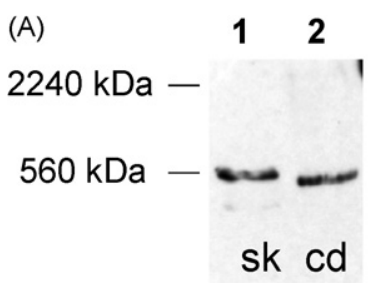

(B)

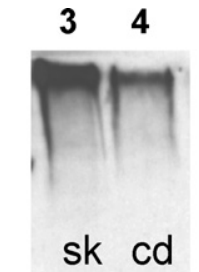

(C)

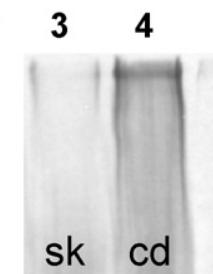

Fig. 7 - Cross-linking analysis of GSTM2-2 $\mathrm{H} 5678$ and RyR interactions. All cross-linking experimental procedures are described in Section 2. Panels (A) and (B) are Western blots using anti-RyR antibody. Panel (C) is [ $\left.{ }^{35} \mathrm{~S}\right]$ radiography. Panel (A) shows skeletal (sk) and cardiac (cd) SR that has not been cross-linked; Lane 1, $2 \mu \mathrm{g}$ of skeletal SR; lane 2, $60 \mu \mathrm{g}$ of cardiac SR. Panel (B) shows RyR after incubation of SR with ${ }^{35}$ S]methonine labelled H5678 followed by cross-linking; Lane 3, $22 \mu$ g of skeletal SR plus [ ${ }^{35}$ S] H5678; lane 4, $62 \mu$ g of cardiac SR plus $\left[{ }^{35}\right.$ S]H5678. Panel (C) shows a radiograph of the SDS-PAGE showing $\left[{ }^{35}\right.$ S]methionine labelled $\mathrm{H} 5678$ after incubation with SR and subsequent cross-linking; lanes 3 and 4 are the same as in (B). Lane 5, shows $\left[{ }^{35} \mathrm{~S}\right] \mathrm{H} 5678$ after the cross-linking reaction in the absence of SR. The amounts of SR added to the lanes were varied to best show the protein and to correct for the smaller amounts of RyR in the cardiac SR preparation. The amount of skeletal muscle RyR1 was increased in the cross-linking experiment to ensure that any weak binding would be detected. 
apparent from Fig. 7B that there was notably more RyR1 in the skeletal muscle SR preparation than RyR2 in the cardiac SR preparation. This significant difference in binding of GSTM2-2 H5678 to RyR1 and RyR2 is consistent with the different actions of GSTM2-2 on RyR1 and RyR2. However the binding between H5678 and RyR2 is weak as demonstrated by the rapid reversibility of the functional effects of the protein when it was washed from the bath. This was also seen in the failure to demonstrate binding of the ${ }^{35} \mathrm{~S}$ labelled H5678 fragment in the absence of cross-linker and an inability of RyR2 to immunoprecipitate the H5678 fragment.

\subsection{The Tyr7Phe substitution}

Previous experiments indicated that active site cysteine residues were important in the inhibitory effect of GSTO1-1 and CLIC-2 on cardiac RyR2 but not the excitatory effects in skeletal RyR1 channels [1-3]. Since the effects on RyR2 channels could be reversed by washing the proteins out of the cis solution, disulphide bonds could not have been formed and it was concluded that structural effects of modifying the cysteine residues were responsible for reducing the inhibitory effects [1]. It was of interest to determine whether the active site structure is also required for the action of the GSTM2-2 on RyR2; we replaced tyrosine 7 with phenylalanine in GSTM2-2Y7F. Tyr7 is an essential active site residue in GSTM2-2 and substitution of this residue with Phe should abolish its enzymatic activity and may alter the structure of the site [21]. The average data in Fig. 8A shows that inhibition of $\mathrm{Ca}^{2+}$ release with $3 \mu \mathrm{M}$ of the GSTM2-2Y7F construct was significant, but less than wild-type GSTM2-2. There was a trend towards reduced activity with $15 \mu \mathrm{M}$ GSTM2-2Y7F, but the inhibition was not significant. $\mathrm{Ca}^{2+}$ release from skeletal SR vesicles was not altered by $3 \mu \mathrm{M}$ or $15 \mu \mathrm{M}$ of either the wild-type GSTM2-2 or GSTM2-2Y7F (Fig. 8D).

The cardiac RyR2 currents in Fig. 8B show that the channel was marginally less active during application of $5 \mu \mathrm{M}$ GSTM22Y7F to the cytoplasmic solution than it was before application of the protein or after its washout. The average relative open probability of RyR2 channels showed a small but significant reduction with GSTM2-2Y7F at $5 \mu \mathrm{M}$, but no significant change with $15 \mu \mathrm{M}$ (hatched bins Fig. $8 \mathrm{C}$ ). The reduction in activity with $5 \mu$ M GSTM2-2Y7F was significantly less than previously reported for the wild-type GSTM2-2 (filled bins in Fig. 8C, data from Fig. 2 is included for comparison). Skeletal RyR1 channels are activated when wild-type GSTM2-2 is added to the cytoplasmic (cis) solution [4], and were also activated GSTM2-2Y7F (Fig. 8E and F). The increase in activity with the mutant constructs was reversed when the protein was perfused from the cis chamber (Fig. 8E), as was the increase with the wild-type protein [4]. The average data in Fig. 8F shows that the activation induced by $30 \mu \mathrm{M}$ GSTM2-2Y7F was very similar to that induced by $30 \mu \mathrm{M}$ of the wild-type protein. Lower concentrations of GSTM2-2Y7F ( $5 \mu \mathrm{M}$ and $15 \mu \mathrm{M})$ also activated skeletal RyR1 channels, with a trend towards a greater average increase in relative open probability with lower concentrations of protein (Fig. 2D). Indeed the effect of GSTM2-2Y7F at $5 \mu \mathrm{M}$ was significantly greater than the effect of $30 \mu \mathrm{M}$ of the wild-type protein.
These results with GSTM2-2Y7F are consistent with the previously reported actions of changes in the active site of GSTO1-1 [1] and suggest that the active site structure contributes to the inhibitory action of members of the GST structural family on RyR2 channel activity. The active site may also influence the actions of GSTM2-2 on skeletal RyR1 channels, since activity of RyR1 tended to be greater with GSTM2-2Y7F.

\section{Discussion}

We describe a novel structural study of the muscle specific GSTM2-2 which was performed to discover the region of the GST responsible for inhibition of the cardiac RyR2 ion channel. We found that the inhibitory action of GSTM2-2 is fully supported by the C-terminal half of the protein (GSTM2-2C). GSTM2-2C was highly specific for the cardiac RyR channel, since it had no effect on skeletal RyR1 channels.

\subsection{The binding site for RyRs on GSTM2-2}

The results show conclusively that the site on GSTM2-2 that interacts with the cardiac RyR2 and inhibits the channel is located in the C-terminal half of the protein. We show that helix 6 is central to the inhibitory action of GSTM2-2 on RyR2 since only those constructs containing the helix 6 sequence were active on $\mathrm{Ca}^{2+}$ release from cardiac SR. The data further suggests that the structure as well as the sequence of the helix 6 residues is important in function, since the unstructured helix 6 peptide had limited activity. The most active constructs contained the helix 6 sequence plus sequences corresponding to two or more neighbouring helices and the CD spectra indicated that these constructs contained a higher $\alpha$-helical content than less active constructs. It is likely that the helical structure of the helix 6 sequence is stabilized by the surrounding sequences or helices in the longer constructs so that the surrounding sequences are necessary for the maximum functional efficiency of the protein. It is not clear whether the structured helix 6 alone is the actual site of interaction with RyR2, or whether helices 5, 7 or 8 also contribute to the interaction site. The lack of effect of any of the C-terminal constructs on skeletal RyR1 channels indicates that the part of GSTM2-2 that interacts with RyR1 and activates the skeletal channel is located in the N-terminal half of the protein.

\subsection{Therapeutic potential of GSTM2-2 based compounds}

This study provides the first step towards identifying the inhibitory site on GSTM2-2. Further studies will be required to identify the interacting residues. We speculate that compounds based on the structure of the interacting segment of GSTM2-2 would be more effective in modifying contraction in the heart than in modifying the function of other tissues. Firstly, the compounds would not be active in skeletal muscle. Secondly, since RyR2 is essential for $\mathrm{Ca}^{2+}$ release from cardiac $\mathrm{SR}$, cardiac contraction is exquisitely sensitive to changes in RyR2 activity. This is in contrast to other tissues, where there appear to be redundancies in the sources of $\mathrm{Ca}^{2+}$, as more than 


\section{cardiac}

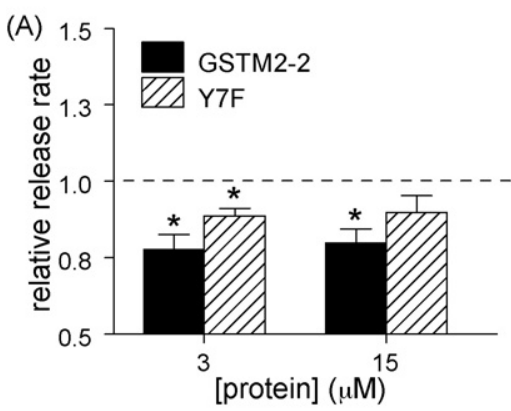

(B)
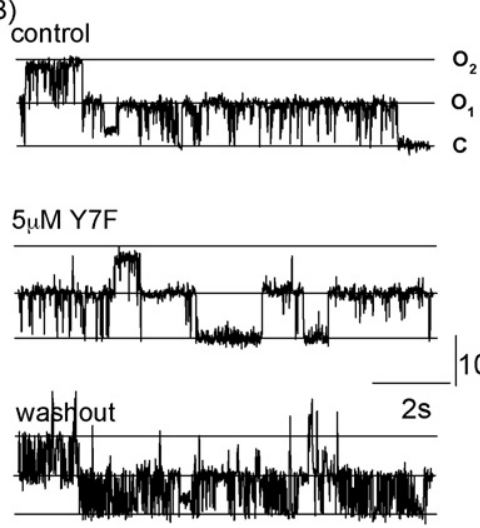

(C)

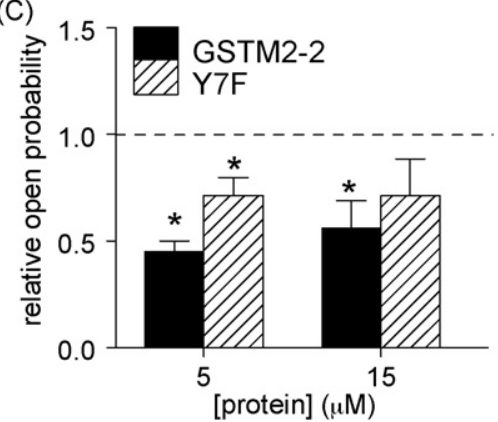

skeletal

(D)

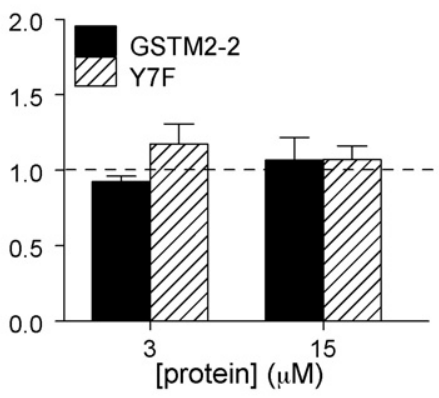

(E)
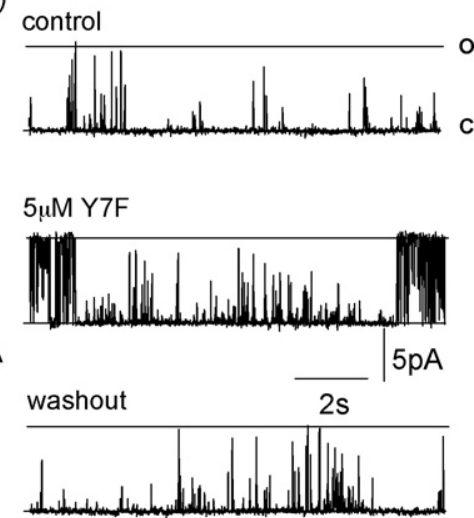

(F)

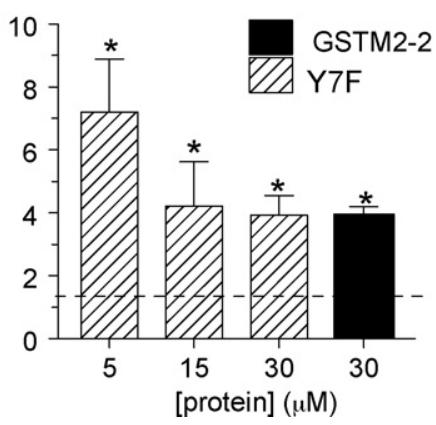

Fig. 8 - Effects of mutation of the active site residue $\mathrm{Y} 7$ on cardiac RyR2 and skeletal RyR1 channels. Average relative rate of caffeine-induced $\mathrm{Ca}^{2+}$ release from cardiac (A) or skeletal (D) SR in the presence of wild-type GSTM2-2 (filled bin) or GSTM22Y7F (hatched bins) at concentrations of $3 \mu \mathrm{M}$ and $15 \mu \mathrm{M} . \mathrm{N}=5-6$ for each data set. $10 \mathrm{~s}$ records from cardiac RyR2 (B) and skeletal RyR1 (E) channels at $+40 \mathrm{mV}$, during the period before addition of $5 \mu \mathrm{M}$ GSTM2-2Y7F to the cis chamber (control), in the presence of the protein (Y7F) and after perfusion of the cis chamber to remove the protein (washout). (C and F) show average data from channels exposed to either the wild-type GSTM2-2 (as in Fig. 2, included for comparison) or to GSTM22Y7F (hatched bins). The mutation reduces the ability of GSTM2-2 to inhibit RyR2 (C) but does not alter the ability of $30 \mu M$ of the protein to activate RyR1 (F). Channel opening is upward from the closed level (c) to the maximum single channel current (o). When two channels are present in the bilayer, one opens alone to a maximum current of $o_{1}$ or two channels open simultaneously to $\mathrm{O}_{2}$. Data from four to seven experiments was analysed for each data set. Asterisks (*) indicate values that are significantly different from control.

one RyR isoform is often expressed and IP3 sensitive $\mathrm{Ca}^{2+}$ stores are present in the same cells $[22,23]$. Thus the selective inhibition of RyR2 by the C-terminal half of GSTM2-2 has significant clinical potential in the treatment of chronic heart failure where RyR2 channels can become abnormally active, inducing arrhythmias and reducing $\mathrm{Ca}^{2+}$ store filling during diastole and contractility. The success of the drug JTV519 in stabilizing FKBP/RyR interactions and improving cardiac muscle function in heart failure in mice [24] has shown that the RyR is an effective therapeutic target for heart failure. It is likely that drugs based on the structure of the RyR binding domain in GSTM2-2 be more specific than JTV519. It is highly 
significant that some of the C-terminal domain fragments are considerably more active than the native GSTM2-2 molecule. This indicates that an active peptide or peptide mimetic may be effective in the presence of endogenous GSTM2-2, since it would displace the endogenous protein and exaggerate its inhibitory action. It is also significant that an active peptide based on the endogenous GSTM2-2 would be less immunogenic than a foreign protein.

\subsection{Physiological significance}

The cardiac RyR2 has a lower affinity than RyR1 for inhibition by $\mathrm{Mg}^{2+}$ [25] and thus the heart depends on endogenous inhibitory compounds like GSTs to depress channel activity during diastole. Understanding the molecular mechanism of GST-induced inhibition of RyR2 is crucial to understanding the mechanisms that depress RyR2 activity in the heart and conserve $\mathrm{Ca}^{2+}$ store load to maintain contractility. The present study reinforces previous observations of interactions between the muscle specific GSTM2-2 and the cardiac RyR2 [4]. Although we have not demonstrated that the two proteins interact in the cell, it is unlikely that two proteins present in high concentrations in the cytoplasm [4] would not interact when they do interact in vitro in binding and functional assays. Many compounds assumed to interact with RyR channels in vivo, have not been directly demonstrated to interact with each other in the cell. These include common agents such as ATP, cyclic ADP-ribose, $\mathrm{Mg}^{2+}$ and $\mathrm{Ca}^{2+}$. Indeed, in these cases the evidence supporting in vivo interactions is in fact provided by the in vitro interactions.

\subsection{How does the N-terminal active site influence the inhibitory action of GSTM2-2}

Despite the overwhelming evidence that the critical site for inhibition of RyR2 is located in the C-terminal half of GSTM2-2, the N-terminus also appears to influence activity. Two previous experiments have suggested that the active site cysteine residue affects the ability of GSTO1-1 to inhibit RyR2. Firstly, when GSTO1-1 was treated with N-ethylmaleimide, it lost both its enzyme activity and its ability to inhibit RyR2. In a second type of experiment, GSTO1-1 with a Cys-32 $\rightarrow$ Ala mutation that removed enzyme activity lost its ability to depress RyR2 activity [1]. This was thought to be an influence of the cytsteine residues on structure, rather than disulphide formation, since the effects reverse when the compounds are washed out. The effect of the active site mutation in GSTM2-2 (GSTM2-2Y7F) also indicates that RyR2 inhibition by the Cterminal half is influenced by the $\mathrm{N}$-terminal domain. The influence of the N-terminal parts of GSTM2-2 on its inhibition of RyR2 could be due to their influence on the arrangement of the $\mathrm{C}$-terminal helices and on the $\mathrm{C}$-terminal residues that bind to RyR2. An occlusion by the $\mathrm{N}$-terminal residues in the full length protein is suggested by the observation that H5678, and to some extent GSTM2-2C, caused stronger inhibition of RyR2 channels than that of the full length GSTM2-2.

The activation of RyR1 channels by $3 \mu \mathrm{M}$ and $15 \mu \mathrm{M}$ of the wild-type GSTM2-2 and GSTM2-2Y7F is in contrast to the lack of effect of the proteins on $\mathrm{Ca}^{2+}$ release from SR. Similar stronger effects on RyR2 channel activity than on $\mathrm{Ca}^{2+}$ release were seen with most C-terminal constructs. Higher concentrations of other compounds are also required to produce effects on $\mathrm{Ca}^{2+}$ release that are equivalent to effects on RyR channels in bilayers [17]. This difference may be related to differences between the conditions in two types of experiment.

\subsection{Summary}

The results show that the ability of GSTM2-2 to specifically inhibit cardiac RyR2 channels depends on the structural integrity of the C-terminal part of the protein, with helix 6 playing a critical role in the inhibition of RyRs. These observations provide the first basic structural information on the specific interaction between GSTM2-2 and the cardiac RyR channel complex. These results raise the future possibility of using the interacting residues in the C-terminal part of GSTM2-2 as a template for drugs to depress RyR2 function when the channel is hyperactive in heart failure.

\section{Acknowledgements}

The authors are grateful to Suzy Pace and Joan Stivala for assistance with preparation of SR vesicles. The work was funded by grants \#268027 and \#471462 from the Australian National Health and Medical Research Council.

\section{R E F E R E N C E S}

[1] Dulhunty A, Gage P, Curtis S, Chelvanayagam G, Board P. The glutathione transferase structural family includes a nuclear chloride channel and a ryanodine receptor calcium release channel modulator. J Biol Chem 2001;276:3319-23.

[2] Board PG, Coggan M, Watson S, Gage PW, Dulhunty AF. CLIC-2 modulates cardiac ryanodine receptor $\mathrm{Ca}^{2+}$ release channels. Int J Biochem Cell Biol 2004;36:1599-612.

[3] Dulhunty AF, Pouliquin P, Coggan M, Gage PW, Board PG. A recently identified member of the glutathione transferase structural family modifies cardiac RyR2 substate activity, coupled gating and activation by $\mathrm{Ca}^{2+}$ and ATP. Biochem J 2005;390:333-43.

[4] Abdellatif Y, Liu D, Gallant EM, Gage PW, Board PG, Dulhunty AF. The Mu class glutathione transferase is abundant in striated muscle and is an isoform-specific regulator of ryanodine receptor calcium channels. Cell Calcium 2007;41:429-40.

[5] Jalilian C, Gallant EM, Board PG, Dulhunty AF. Redox potential and the response of cardiac ryanodine receptors to CLIC-2, a member of the glutathione S-transferase structural family. Antioxid Redox Signal 2008;10:1675-86.

[6] Sambrook J, Fritsch EF, Maniatis T. Molecular cloning: a laboratory manual. NY: Cold Spring Harbor Laboratory; 1989.

[7] Ross VL, Board PG. Molecular cloning and heterologous expression of an alternatively spliced human Mu class glutathione S-transferase transcript. Biochem J 1993;294(Pt 2):373-80.

[8] Catanzariti AM, Soboleva TA, Jans DA, Board PG, Baker RT. An efficient system for high-level expression and easy purification of authentic recombinant proteins. Protein Sci 2004;13:1331-9. 
[9] Baker RT, Catanzariti AM, Karunasekara Y, Soboleva TA, Sharwood R, Whitney S, et al. Using deubiquitylating enzymes as research tools. Methods Enzymol 2005;398: 540-54.

[10] Laemmli UK. Cleavage of structural proteins during the assembly of the head of bacteriophage T4. Nature 1970;227:680-5.

[11] Wei L, Abdellatif YA, Liu D, Kimura T, Coggan M, Gallant EM, et al. Muscle-specific GSTM2-2 on the luminal side of the sarcoplasmic reticulum modifies RyR ion channel activity. Int J Biochem Cell Biol 2008;40:1616-28.

[12] Dulhunty AF, Cengia L, Young J, Pace SM, Harvey PJ, Lamb GD, et al. Functional implications of modifying RyRactivating peptides for membrane permeability. $\mathrm{Br} \mathrm{J}$ Pharmacol 2005;144:743-54.

[13] Minium EW, King BM, Bear G. Statistical reasoning in psychology and education. New York: John Wiley and Sons; 1993.

[14] Raghunathan S, Chandross RJ, Kretsinger RH, Allison TJ, Penington CJ, Rule GS. Crystal structure of human class mu glutathione transferase GSTM2-2. Effects of lattice packing on conformational heterogeneity. J Mol Biol 1994;238:815-32.

[15] McCallum SA, Hitchens TK, Rule GS. Solution structure of the carboxyl terminus of a human class Mu glutathione Stransferase: NMR assignment strategies in large proteins. J Mol Biol 1999;285:2119-32.

[16] Lu X, Xu L, Meissner G. Activation of the skeletal muscle calcium release channel by a cytoplasmic loop of the dihydropyridine receptor. J Biol Chem 1994;269:6511-6.

[17] Dulhunty AF, Laver DR, Gallant EM, Casarotto MG, Pace SM, Curtis S. Activation and inhibition of skeletal RyR channels by a part of the skeletal DHPR II-III loop: effects of DHPR Ser687 and FKBP12. Biophys J 1999;77:189-203.

[18] Dulhunty AF, Laver D, Curtis SM, Pace S, Haarmann C, Gallant EM. Characteristics of irreversible ATP activation suggest that native skeletal ryanodine receptors can be phosphorylated via an endogenous CaMKII. Biophys J 2001;81:3240-52.

[19] Murray BE, Ohlendieck K. Cross-linking analysis of the ryanodine receptor and alpha1-dihydropyridine receptor in rabbit skeletal muscle triads. Biochem J 1997;324(Pt 2): 689-96.

[20] Shoshan-Barmatz V, Hadad-Halfon N, Ostersetzer O. Crosslinking of the ryanodine receptor/ $/ \mathrm{Ca}^{2+}$ release channel from skeletal muscle. Biochim Biophys Acta 1995;1237: 151-61.

[21] Penington CJ, Rule GS. Mapping the substrate-binding site of a human class mu glutathione transferase using nuclear magnetic resonance spectroscopy. Biochemistry 1992;31:2912-20.

[22] Van Den Bosch L, Verhoeven K, De Smedt H, Wuytack F, Missiaen L, Robberecht W. Calcium handling proteins in isolated spinal motoneurons. Life Sci 1999;65:1597-606.

[23] Vallot O, Combettes L, Jourdon P, Inamo J, Marty I, Claret M, et al. Intracellular $\mathrm{Ca}^{2+}$ handling in vascular smooth muscle cells is affected by proliferation. Arterioscler Thromb Vasc Biol 2000;20:1225-35.

[24] Wehrens XH, Lehnart SE, Marks AR. Ryanodine receptortargeted anti-arrhythmic therapy. Ann N Y Acad Sci 2005;1047:366-75.

[25] Laver DR, Baynes TM, Dulhunty AF. Magnesium inhibition of ryanodine-receptor calcium channels: evidence for two independent mechanisms. J Membr Biol 1997;156:213-29. 